\title{
Escala de Depressão, Ansiedade e Estresse: propriedades psicométricas e prevalência das afetividades
}

\author{
Depression, Anxiety, and Stress Scale: psychometric \\ properties and affectivity prevalence
}

DO1: $10.1590 / 0047-2085000000222$

J Bras Psiquiatr. 2019;68(1):32-41

Where you read:

\section{Prevalências}

Após atestada a validade e a confiabilidade do modelo da DASS-21 para a amostra, os escores médios de depressão, ansiedade e estresse foram calculados. Baseados nesses escores, os indivíduos foram agrupados, considerando a severidade de depressão, ansiedade e estresse, utilizando pontos de corte propostos pelo autor da escala original ${ }^{3}$ para cômputo da prevalência dessas condições na amostra. As prevalências foram calculadas por ponto e por intervalo de confiança de 95\% (IC 95\%) e comparadas segundo o sexo. Esses pontos de corte foram obtidos a partir dos percentis da escala de resposta aos itens da DASS-21 e estão apresentados na tabela 2.

Tabela 2. Pontos de corte (escore médio) obtidos a partir dos percentis da escala de resposta aos itens da Escala de Depressão, Ansiedade e Estresse (DASS-21), propostos por Lovibond e Lovibond

\begin{tabular}{lccc}
\hline Fator DASS & Percentil & Escore médio & Classificação \\
\hline Depressão & $<$ P78 & $<2,34$ & Normal \\
Ansiedade & P78 $\mid-P 87$ & $2,34 \mid-2,61$ & Leve \\
Estresse & P87|-P95 & $2,61 \mid-2,85$ & Moderada \\
& P95 $\mid-P 98$ & $2,85 \mid-2,94$ & Severa \\
& $\geq P 98$ & $\geq 2,94$ & Extremamente severa \\
\hline
\end{tabular}

Lovibond e Lovibond ${ }^{3}$.
Should read:

\section{Prevalências}

Após atestada a validade e a confiabilidade do modelo da DASS-21 para a amostra, os escores médios de depressão, ansiedade e estresse foram calculados. Baseados nesses escores, os indivíduos foram agrupados, considerando a severidade de depressão, ansiedade e estresse, utilizando pontos de percentis propostos pelo autor da escala original ${ }^{3}$ para cômputo da prevalência dessas condições na amostra. As prevalências foram calculadas por ponto e por intervalo de confiança de 95\% (IC 95\%) e comparadas segundo o sexo. Esses pontos de corte foram obtidos a partir dos percentis da escala de resposta aos itens da DASS-21 e estão apresentados na tabela 2.

Tabela 2. Pontos de corte (escore médio) obtidos a partir dos percentis da escala de resposta aos itens da Escala de Depressão, Ansiedade e Estresse (DASS-21)

\begin{tabular}{lccc}
\hline Fator DASS & Percenti $^{\# \#}$ & Escore Médio $^{\ddagger}$ & Classificação \\
\hline$<P 78$ & $<2,34$ & Normal \\
Depressão & $\mathrm{P} 78 \mid-\mathrm{P} 87$ & $2,34 \mid-2,61$ & Leve \\
Ansiedade & $\mathrm{P} 87 \mid-\mathrm{P} 95$ & $2,61 \mid-2,85$ & Moderada \\
Estresse & $\mathrm{P} 95 \mid-\mathrm{P} 98$ & $2,85 \mid-2,94$ & Severa \\
& $\geq \mathrm{P98}$ & $\geq 2,94$ & Extremamente severa \\
\hline
\end{tabular}

${ }^{*}$ Lovibond SH, Lovibond PF ${ }^{3}$

¥Esses percentis foram transpostos para a escala de respostas variando de 0 a 3 . 